\title{
RESIDÊNCIA DE ENFERMAGEM EM PSIQUIATRIA E SAÚDE MENTAL: PERSPECTIVAS SOBRE FORMAÇÃO E CAMPO DE TRABALHO
}

\author{
NURSING RESIDENCY IN PSYCHIATRY AND \\ MENTAL HEALTH: PERSPECTIVES ON TRAINING \\ AND LABOR FIELD
}

\section{RESIDENCIA DE ENFERMERÍA EN PSIQUIATRÍA Y SALUD MENTAL: PERSPECTIVAS SOBRE LA FORMACIÓN Y EL CAMPO DE TRABAJO}

\author{
John Victor dos Santos Silva ${ }^{1}$ \\ Thyara Maia Brandão ${ }^{2}$ \\ Amanda Cavalcante de Macêdo ${ }^{3}$ \\ Keila Cristina Pereira do Nascimento Oliveira ${ }^{4}$ \\ Mara Cristina Ribeiro 5 \\ Ronildo Alves dos Santos ${ }^{6}$
}

Como citar este artigo: Silva JVS, Brandão TM, Macêdo AC, Oliveira KCPN, Ribeiro MC, Santos RA. Residência de enfermagem em psiquiatria e saúde mental: perspectivas sobre formação e campo de trabalho. Rev baiana enferm. 2021;35:e39080.

Objetivo: descrever a perspectiva de enfermeiros egressos de um programa de residência de Enfermagem em Psiquiatria e Saúde Mental em Alagoas sobre a formação e o campo de trabalho. Método: estudo exploratório, qualitativo, realizado com dez enfermeiros egressos de um programa de residência de Enfermagem em Psiquiatria e Saúde Mental no Nordeste do Brasil. Foram realizadas entrevistas semiestruturadas com gravação de áudio. Os dados foram submetidos à análise de conteúdo temática e discutidos à luz dos referenciais teóricos da Reforma Psiquiátrica e da Enfermagem em Saúde Mental. Resultado: as categorias temáticas identificadas foram "Processo de Formação: expectativas versus realidade" e "Campo de Trabalho: oportunidades e satisfação profissional". Considerações finais: em relação à formação, os enfermeiros egressos sentiam-se satisfeitos com o conhecimento proporcionado pela residência; em relação ao campo de trabalho, manifestaram frustração por não serem aproveitados, mesmo sendo profissionais especializados e aptos para contribuir para a qualificação do serviço.

Descritores: Enfermagem. Internato não Médico. Enfermagem Psiquiátrica. Saúde Mental. Serviços de Saúde Mental.

\footnotetext{
Enfermeiro. Universidade de São Paulo. Ribeirão Preto, São Paulo, Brasil. john.setedejulho@gmail.com. http://orcid.org/0000-0003-467| - I02X.

Enfermeira. Mestre em Enfermagem. Professora da Universidade Estadual de Ciências da Saúde de Alagoas. Maceió, Alagoas, Brasil. http://orcid.org/0000-00034630-6956.

Enfermeira. Doutora em Linguística. Professora da Universidade Estadual de Ciências da Saúde de Alagoas. Maceió, Alagoas, Brasil. http://orcid.org/0000-00024630-277I.

4 Enfermeira. Doutora em Serviço Social. Professora da Universidade Federal de Alagoas. Maceió, Alagoas, Brasil. http://orcid.org/0000-0003-0167-5889.

5 Terapeuta Ocupacional. Doutora em Ciências. Pró-Reitora de Pesquisa e Pós-Graduação da Universidade Estadual de Ciências da Saúde de Alagoas. Maceió, Alagoas, Brasil. http://orcid.org/0000-000 I-6963-8I58.

6 Filósofo. Doutor em Filosofia. Professor da Escola de Enfermagem de Ribeirão Preto da Universidade de São Paulo. Ribeirão Preto, São Paulo, Brasil. http://orcid. org/0000-0003-3364-7727.
} 
Objective: to describe the perspective of nurses graduated from a residency program of Psychiatry and Mental Health Nursing in Alagoas on training and the labor field. Method: exploratory, qualitative study conducted with ten nurses graduated from a nursing residency program in Psychiatry and Mental Health in northeastern Brazil. Semistructured interviews were conducted with audio recording. The data were submitted to thematic content analysis and discussed in the light of the theoretical references of psychiatric reform and mental health nursing. Result: the thematic categories identified were "Training Process: expectations versus reality" and "Labor Field: opportunities and professional satisfaction". Final thoughts: in relation to education, the graduated nurses were satisfied with the knowledge provided by the residency; in relation to the labor field, they expressed frustration at not being valued, despite being specialized professionals able to contribute to the qualification of the service.

Descriptors: Nursing. Internship, Nonmedical. Psychiatric Nursing. Mental Health. Mental Health Services.

Objetivo: describir la perspectiva de las enfermeras graduadas de un programa de residencia de Enfermería en Psiquiatría y Salud Mental en Alagoas sobre la formación y el campo de trabajo. Método: estudio exploratorio y cualitativo realizado con diez enfermeras graduadas de un programa de residencia de enfermería en Psiquiatría y Salud Mental en el noreste de Brasil. Se realizaron entrevistas semiestructuradas con grabación de audio. Los datos fueron sometidos a análisis temáticos de contenidos y discutidos a la luz de las referencias teóricas de la reforma psiquiátrica y la enfermería de salud mental. Resultado: las categorías temáticas identificadas fueron "Proceso de Formación: expectativas versus realidad" y "Campo Laboral: oportunidades y satisfacción profesional". Consideraciones finales: en relación con la educación, las enfermeras graduadas estaban satisfechas con los conocimientos proporcionados por la residencia; en relación con el campo del trabajo, expresaron su frustración por no ser pulsadas, a pesar de su especialización profesional y capacidad de contribuir a la calificación del servicio.

Descriptores: Enfermería. Internado no Médico. Enfermería Psiquiátrica. Salud Mental. Servicios de Salud Mental.

\section{Introdução}

A assistência em saúde mental no Brasil tem uma história longa de discussões, propostas e experiências bem-sucedidas na transformação de uma assistência centrada no hospital psiquiátrico para uma ampla rede descentralizada. Esta rede tem gerenciado o tratamento, a assistência, o acompanhamento, a reabilitação psicossocial e promoção da cidadania a pessoas em sofrimento mental no âmbito do Sistema Único de Saúde (SUS), em conjunto com as demais esferas das políticas públicas, resultado do processo de movimento da Reforma Psiquiátrica no Brasil ${ }^{(1)}$.

A Rede de Atenção Psicossocial (RAPS) representa, hoje, esse modelo de gerenciamento do cuidado em saúde mental no Brasil, para as pessoas com transtornos mentais. Ao articular atenção básica, especializada, de reabilitação psicossocial, economia solidária e urgência e emergência, promove a integralidade do cuidado apoiado em uma articulação intersetorial entre saúde, educação, economia e segurança, entre outros ${ }^{(1)}$.

A RAPS torna-se também responsável pela capacitação dos trabalhadores do SUS e formação dos futuros profissionais generalistas e especialistas na perspectiva da integralidade do cuidado, pautadas nos fundamentos da Reforma Psiquiátrica e das Políticas Públicas em Saúde Mental. Uma das estratégias utilizadas para a formação de profissionais e que promove o fortalecimento do SUS e da RAPS são as Residências em Saúde ${ }^{(1-2)}$.

Os programas de Residência em Saúde foram criados tendo em vista a formação de recursos humanos que possam atender à complexidade dos serviços de saúde. Consideram as políticas públicas indutoras de educação no trabalho e pelo trabalho no SUS, que visam capacitar trabalhadores para o oferecimento da atenção integral, seja de forma uniprofissional, seja multiprofissional ou interdisciplinar. Na conclusão, essa formação concede ao egresso o título de especialista na área do programa ${ }^{(3)}$.

As Residências em Saúde são regulamentadas e autorizadas pelo Ministério da Educação. São ofertadas por Instituições de Ensino Superior ou por serviços de saúde, tendo como finalidade a formação pela constante prática no trabalho. Embora possuam regimento específico, 
os programas de residência organizam-se e estruturam-se individualmente, baseados nas normas institucionais e de acordo com a dinâmica e disposição da rede de saúde e de serviços no território, apresentando características e recursos diversos ${ }^{(2,4)}$.

Na área da saúde mental, destacam-se os programas de residência em Enfermagem Psiquiátrica e em Saúde Mental. Estes colaboram para a capacitação de enfermeiros especialistas e possibilitam o reconhecimento da contribuição da Enfermagem no campo de trabalho e como alternativa de qualificação de mão de obra nos serviços especializados na atenção à pessoa em sofrimento mental. São exemplos os Centros de Atenção Psicossocial (CAPS), como os demais serviços que incorporam a RAPS ${ }^{(2)}$.

Entendendo a importante contribuição desses programas no fortalecimento do SUS e no desenvolvimento das práticas no cuidado em saúde mental, o presente estudo apresenta como objeto de investigação a perspectiva do enfermeiro egresso do programa de residência de Enfermagem em Psiquiatria e Saúde Mental sobre o seu processo de formação e campo de trabalho. Nesse contexto, a motivação pela escolha do assunto investigado deu-se pela aproximação dos autores com a temática e a necessidade de compreensão sobre o processo de formação do enfermeiro residente e suas possibilidades no campo de atuação.

Para alicerçar o aprofundamento do estudo, utilizaram-se os referenciais teóricos da Reforma Psiquiátrica e da Enfermagem em Saúde Mental. Desta forma, a Reforma Psiquiátrica, que se utiliza como lente teórica neste artigo, compreende que o movimento de transformação paradigmática é contínuo e atualiza-se na articulação com diferentes saberes, serviços e setores. Seu objetivo é potencializar respostas às necessidades de (re)inserção das pessoas que recebem cuidados nos serviços de saúde mental, estendendo o campo de cuidado em saúde mental para uma perspectiva complexa, multidimensional, interdisciplinar e intersetorial ${ }^{(1)}$.

A Enfermagem em Saúde Mental, área científica, de formação continuada e atuação profissional, deve estar alinhada a essas proposições da Reforma Psiquiátrica. O processo de formação deve estar voltado para o desenvolvimento de competências e habilidades, para a construção de práticas e saberes que possibilitem respostas aos princípios propostos pela Reforma Psiquiátrica. Deve também estar em consonância com a Política Nacional de Saúde Mental e comprometido com as mudanças nas ações pedagógicas que envolvam o modelo tradicional de atenção da Enfermagem Psiquiátrica e em Saúde Mental ${ }^{(5)}$.

Diante do exposto, a realização deste estudo fundamenta-se no compromisso social estabelecido entre trabalhadores de Enfermagem e usuários do SUS e vai de encontro às políticas de desmonte do SUS, especialmente as direcionadas à Saúde Mental, reforçando a importância do fortalecimento da luta antimanicomial e da rede de saúde.

Deste modo, o presente estudo tem como objetivo descrever a perspectiva de enfermeiros egressos de um programa de residência de Enfermagem em Psiquiatria e Saúde Mental em Alagoas sobre sua formação e campo de trabalho.

\section{Método}

Trata-se de estudo exploratório de abordagem qualitativa, que permite um aprofundamento nas subjetividades, de forma a compreender as percepções e os sentidos atribuídos a determinada temática ou fenômeno, com base nas experiências de vida ${ }^{(6)}$.

Para nortear o delineamento e assegurar o rigor metodológico deste estudo, utilizou-se o guia da Consolidated Criteria for Reporting Qualitative Research (COREQ) ${ }^{(7)}$.

A Residência em Enfermagem em Psiquiatria e Saúde Mental, que serviu como referência e cenário desta investigação, está vinculada a uma universidade pública em Alagoas. Tem como finalidade formar profissionais enfermeiros especialistas na assistência e no cuidado de pacientes que estão institucionalizados em hospitais psiquiátricos e usuários dos serviços comunitários de saúde mental. O programa iniciou suas 
atividades em 2007, ofertando anualmente duas vagas. Os profissionais aprovados desenvolvem suas atividades num período de dois anos. Até o início de 2018, o programa formou uma média de 20 enfermeiros especialistas.

Participaram do estudo 10 enfermeiros egressos desse Programa de Residência de Enfermagem em Psiquiatria e Saúde Mental de Alagoas, Brasil. Foram incluídos no estudo todos os que concluíram o programa de residência até fevereiro de 2018 - escolhido por ser o mês em que geralmente se encerra o ciclo dos residentes, com entrada de nova dupla no mês seguinte - e excluídos os que estivessem em qualquer tipo de licença médica durante a coleta de dados. Como técnica de amostragem, foi utilizada a contraste-saturação ${ }^{(8)}$. Determinou-se o número final da amostra, quando as percepções, os sentidos e as experiências tornaram-se redundantes e repetitivas.

A coleta ocorreu entre abril e agosto de 2018. Foi realizado contato prévio com a Supervisão de Pós-Graduação lato sensu da universidade do estudo, a fim de levantar nomes e contatos dos egressos. Após o primeiro contato por telefone, os egressos foram convidados para participar da pesquisa de forma individual. As entrevistas foram concedidas nos ambientes escolhidos pelos próprios participantes, levando em consideração o conforto e o mínimo de alteração em suas rotinas. Para a entrevista, foi utilizado roteiro semiestruturado contendo 10 questões produzidas pelos entrevistadores e baseadas no objetivo da pesquisa. Foi realizada a gravação em áudio, por meio de aparelho eletrônico, com autorização dos enfermeiros. O tempo médio das entrevistas foi de 30 minutos.

Os dados foram transcritos na íntegra e analisados à luz da técnica de Análise de Conteúdo, na modalidade Análise Temática ${ }^{(6)}$, definida como um desmembramento e agrupamentos de unidades das falas dos sujeitos em temas que são organizados de forma sistemática e de acordo com os objetivos da pesquisa. A análise aconteceu em três etapas distintas, como é proposto pela modalidade: pré-análise; exploração do material; e tratamento dos resultados.
$\mathrm{Na}$ pré-análise foi realizada a leitura flutuante das transcrições das entrevistas em busca das chamadas unidades das falas, que refletem experiências e percepções dos sujeitos que respondem ao objetivo do estudo. Na etapa de exploração do material, foram atribuídas algumas unidades de contexto, que são os sentidos que foram emergindo ao longo da análise. No tratamento dos resultados, as unidades de contexto foram agrupadas em categorias temáticas, de acordo com os sentidos expressados e encontrados nas unidades das falas dos participantes ${ }^{(6)}$.

A pesquisa seguiu os preceitos éticos estabelecidos pela Resolução n 510/2016/CNS e recebeu aprovação do Comitê de Ética em Pesquisa (CEP) da Universidade Estadual de Ciências da Saúde de Alagoas (UNCISAL), sob o Parecer $\mathrm{n}^{\mathrm{o}} 2.604 .357$.

Aos participantes foi apresentada a pesquisa, seus objetivos, procedimentos metodológicos, por meio da entrega e assinatura do Termo de Consentimento Livre e Esclarecido (TCLE). Para garantir o sigilo e o anonimato dos participantes, foi atribuído como palavra-código o termo "egresso", seguido de um número de 1 a 10, atribuído de forma aleatória.

\section{Resultados}

Participaram deste estudo dez enfermeiros, sendo nove do gênero feminino e um do gênero masculino. Todos tinham idade na faixa de 25 a 30 anos e residiam na cidade onde o estudo foi desenvolvido. Todos realizaram a graduação em enfermagem em instituição de ensino superior pública. Quanto ao ano de formação no programa de residência, um participante concluiu o curso em cada um dos anos de 2009, 2011, 2012, 2014, 2015 e 2016; em 2017 e 2018, dois concluíram.

Dos 10 enfermeiros entrevistados, quatro estavam trabalhando na docência, três estavam fazendo pós-graduação stricto senso em nível de mestrado, um estrava trabalhando na assistência em atenção básica, um não estava atuando na área da enfermagem e outro estava desempregado. Destes, apenas três estavam atuando no setor público e seis no setor privado. 
A análise dos dados possibilitou o surgimento de duas categorias: Processo de Formação: Expectativa versus Realidade; e Campo de Trabalho: Oportunidades e Satisfação Profissional. Os resultados e as categorias foram discutidos à luz da literatura científica sobre a Reforma Psiquiátrica e a Enfermagem em Saúde Mental.

\section{Processo de Formação: Expectativas versus Realidade}

Durante a análise das falas, verificou-se que grande parte dos participantes rememorou informações relacionadas ao período de dois anos de duração da residência. Os participantes relataram que, ao ingressarem no programa, tinham uma expectativa diferente sobre a residência e os cenários de prática nos quais estariam inseridos.

Sobre os cenários de prática, por tratar-se de uma residência de Enfermagem em Psiquiatria e Saúde Mental, eles narraram que percorreram os serviços da RAPS implementada em Alagoas, desde os Centros de Atenção Psicossocial (CAPS) até o serviço hospitalar de referência. A possibilidade de atuar em diferentes serviços da RAPS proporcionou reflexões sobre o modelo atual de atenção à saúde e o anterior à reforma psiquiátrica. Este aspecto pode ser visualizado no relato do Egresso 5:

\footnotetext{
A residência [...] é em Enfermagem em Psiquiatria e Saúde Mental; então, a gente passou um tempo no bospital psiquiátrico que, para mim, foi uma experiência muito chocante, e depois a gente vai para os serviços comunitários de Saúde Mental, os CAPS [Centro de Atenção Psicossociall. Então, essa mistura dos dois campos de atuação faz a gente enxergar a importância da reforma psiquiátrica e perceber que existem, sim, diferenças tanto no trabalbo quanto nos próprios pacientes que estão nesses hospitais e os que estão nos CAPS. É uma diferença enorme.
}

Segundo os participantes, o processo de formação iniciava no hospital psiquiátrico, momento em que a formação não acontecia de forma multiprofissional. Entretanto, no decorrer do curso, houve momentos de aprendizado junto a outros profissionais, como os residentes médicos. Embora a residência Médica e a de Enfermagem sejam programas distintos, na maioria das vezes, as aulas teóricas, discussões e até mesmo algumas práticas aconteciam em conjunto, como se pode verificar na fala do Egresso 1:

Na maioria das vezes, a gente fazia grupos com os residentes de Medicina. Então, a gente tinha a oportunidade de discutir os casos, de aprofundar nossos conbecimentos sobre psicofármacos, psicopatologia, os transtornos em si. Então, foi muito interessante.

Segundo os participantes, as atividades e práticas relacionadas à semiologia dos transtornos mentais, psicopatologias, exame mental, psicofármacos e atenção à crise foram mais enfatizadas no hospital psiquiátrico. O período de permanência no cenário hospitalar variou ao longo dos anos do programa. Nas primeiras turmas, o tempo era um ano, passando para dez meses. Nas últimas turmas, o tempo foi reduzido para um semestre.

Após o período no hospital psiquiátrico, os participantes direcionaram-se para outros serviços de Saúde Mental da RAPS. Atuaram no CAPS infanto-juvenil; no CAPS AD III, para usuários de álcool, crack e outras drogas, em regime de 24 horas; em um dos CAPS II destinados ao atendimento de jovens e adultos; e passaram também pelo Consultório na Rua, e na gestão municipal e estadual em Saúde Mental. Esse período de formação e trabalho, segundo os relatos, foi marcado pela interdisciplinaridade, completando, assim, o processo de formação no programa de residência.

A interdisciplinaridade é o ponto mais forte no trabalho
nos CAPS [Centros de Atenção Psicossocial] e em todos os
serviços de Saúde Mental comunitário que temos no es-
tado. A gente trabalha muito interligada com os demais
profissionais, desde o pessoal que atua "nas terapias"
[Oficinas terapêuticas] até o pessoal do administrativo,
todos contribuem e a gente aprende muito. (Egresso 7).

A autonomia no aprendizado foi um ponto importante mencionado pelos participantes. É um aspecto que caracteriza a formação do enfermeiro no programa de residência. Eles são incentivados, desde os primeiros encontros (antes mesmo de ir ao campo de prática), sob o argumento de que são formados na perspectiva de serem "autodidatas". São instigados a buscar conhecimento teórico e a aplicá-lo no campo de prática. Isso se deve também ao fato de serem poucos os momentos de ensino teórico 
para direcionar a formação desses enfermeiros, sendo bem evidente o aprendizado na prática constante. Tal aspecto pode ser verificado na fala do Egresso 5:

Não tem ninguém ensinando a gente. A gente aprende a
maioria das coisas sozinha mesmo. A gente que constrói
nosso próprio conbecimento teórico e vai testando nas
práticas o que dá e o que não dá certo. A gente não tem
professor. Tudo é a gente mesmo, que busca estratégias
pra aprender, em cursos, em livros, artigos, a gente sem-
pre dá um jeito.

Segundo os participantes, a perspectiva da formação autodidatista fez com eles desenvolvessem uma potencialização para a autocobrança. Também ocorria certa "cobrança" por parte do programa, para que trabalhassem no serviço de forma "produtiva". Mesmo na condição de estudantes do programa, eles carregavam a responsabilidade do exercício profissional como qualquer enfermeiro do serviço.

Você se depara com a responsabilidade de uma enfermeira no serviç. E aî? E essa demanda? E esse paciente? E esse remédio? E você tem que dar conta de tudo, porque eles cobram de você essa responsabilidade e é uma coisa que você acaba também se cobrando. (Egresso 2).

Outra questão bastante evidente nas falas de todos os egressos, refere-se à sobrecarga de trabalho e à exaustão. Eles relataram que a carga horária do programa era bastante "pesada" e que as atividades consumiam muito tempo e esforço.

A carga borária é tão exaustiva que, muitas vezes, faz com que a gente tenha um cansaço tão grande que não consegue ter um melhor aproveitamento que gostariamos. A gente vive cansado o tempo todo! (Egresso 4).

Os participantes ainda apontaram a falta de profissionais enfermeiros capacitados para supervisioná-los no campo e que pudessem conduzi-los nas práticas. Relataram que suas atividades eram supervisionadas pelo enfermeiro preceptor designado para o plantão do dia em que estavam escalados. No entanto, a contribuição desse enfermeiro foi relatada como pouco significativa para o processo de formação da especialidade.

Lá a gente ficava solto. A "sorte" era que a gente se juntava com os residentes de Medicina, os residentes de Psiquiatria, e acompanhava as aulas deles com o professor deles. Mas ter enfermeiro, professor enfermeiro, ensinando a gente, lá não tinha não. (Egresso 2).

Nos serviços comunitários de Saúde Mental, os participantes relataram que sentiram a mesma dificuldade em encontrar profissionais capacitados para contribuir em sua formação teórico-prática, principalmente nas equipes de enfermagem. Em alguns momentos, os participantes mencionaram que eles, os residentes, mais ensinavam aos profissionais do serviço do que aprendiam.

Nos serviços, eles falam para a gente "colar" na enfermeira do CAPS. Mas, muitas vezes, elas não sabem nem o papel delas ali. Várias vezes, a gente que ensinava para a equipe de enfermagem sobre as psicopatologias, sobre os psicofármacos, as terapias, como fazer grupos. Mas a gente não era para estar aprendendo com eles? (Egresso 6).

$\mathrm{Na}$ perspectiva dos participantes do estudo, os profissionais do cenário de prática, muitas vezes, não sabiam exatamente como funcionava a residência, o que acabava gerando um não aproveitamento eficaz dos residentes junto ao serviço, especialmente quanto às demandas assistenciais e gerenciais que emergiam no cenário de prática. Os participantes afirmaram que sentiam como se não houvesse uma programação/planejamento para o seu acolhimento e direcionamento. Os campos de práticas [...] deveriam ser preparados para
receber o residente. Isso já ajudaria muito. Porque, mui-
tas vezes, a equipe [...] não sabe pra quê [...] eu estava
ali; não sabiam que dia a gente iria chegar, até quando
iamos ficar, o que iamos fazer. Então, a gente teve que
ir conquistando espaço, porque os profissionais não sa-
biam direcionar a gente no serviço. A gente que ia pro-
curando o que fazer. (Egresso 8).

Outro aspecto bem evidente nas falas de todos os participantes foi a sensação de falta de organização, linearidade e continuidade das atividades, principalmente relacionadas aos módulos teóricos. Eles referiram a existência de módulos teóricos a serem cumpridos mensalmente, porém esses módulos careciam de organização, e as aulas eram ministradas pelos próprios residentes para os demais e quase sempre nenhum professor estava presente nas aulas teóricas.

Tínhamos alguns módulos em comum com os residentes de outros programas e os módulos específicos da gente. Mas esses módulos [...] não eram, na minha época [...] bem organizados. Eram módulos que nem sempre tinham datas certas no cronograma. Nem cronograma a gente tinha! E era tudo em cima da bora. A gente recebia no dia a informação que no dia seguinte ia ter o módulo. (Egresso 9). 
Algumas dificuldades de relacionamento e entendimento das demandas dos residentes por parte do programa também foi um fator presente nas falas, como comentou o Egresso 10:

\footnotetext{
A gente teve uma coordenação muito rígida e isso dificultava um pouquinho. Eu não sei como é isso nas outras residências, mas eu acho que seria primordial que o coordenador tivesse vivenciado o processo de ser residente, né, de estar inserido ali no campo. Porque tem coisa que só o residente ou quem foi residente é quem sabe onde está apertando, onde as coisas são mais complicadas, né? Até mesmo a forma de enxergar, de conduzir as discussões, de perceber o que é necessário ou não.
}

Embora acessível, os participantes apontaram a existência de alguns aspectos que dificultavam o relacionamento dos residentes com o programa, principalmente a falta de sensibilidade, relacionada ao excesso de atividades, e as cobranças excessivas, que, muitas vezes, proporcionavam exaustão e fadiga nos residentes.

\section{Campo de Trabalho: Oportunidades e Satisfação Profissional}

A segunda categoria identificada está relacionada ao campo de trabalho, no que diz respeito às oportunidades após a formação na residência e à satisfação profissional. Em relação às oportunidades, os participantes comentaram que, para enfermeiros, o campo em saúde mental no estado é incerto, seja em serviço público ou privado.

Durante o período em que estiveram como residentes, os participantes relataram ter passado por todos os serviços de Saúde Mental oferecidos na capital, Maceió, e alguns no interior do estado. Entretanto, após o término, nenhum deles encontrou espaços no campo de trabalho na área assistencial. Pode-se verificar este aspecto nas falas do Egresso 6 e Egresso 5:

\footnotetext{
Até boje eu não tive nenhuma oportunidade que realmente dissesse assim: "essa oportunidade é porque você foi residente em Saúde Mental". E eu tenho amigas que fizeram residência em obstetrícia, urgência e emergência e estão todas trabalhando, enquanto eu tive que partir para outra coisa. (Egresso 6).
}

Para a realidade de Alagoas, eu posso dizer que o campo de trabalbo é inexistente. Porque não tem nenbum ex-residente que trabalhe nos Centros de Atenção Psicossocial daqui, por exemplo. A maioria está partindo pra docência. (Egresso 5).
Além da não oportunidade de trabalho nos serviços de Saúde Mental, os participantes relataram que também é difícil conseguir trabalho nos demais campos da Enfermagem, seja na atenção básica, na especializada ou hospitalar, sendo o ramo da docência uma das poucas alternativas.

Todos os ex-residentes que eu tenho contato foram para a docência. Inclusive, eu estou na docência também, né? Só que essa não é a proposta do programa. A proposta do programa é para formar profissionais especialistas para atuar no serviço. (Egresso 9).

A docência, na percepção dos egressos, é o campo que mais acolhe os antigos residentes. Pelos relatos, verificou-se que alguns escolheram deliberadamente a ida para o campo da docência; já outros consideravam-na como única forma de trabalho disponível. Para os que optaram pela docência, continuaram especializando-se em programas stricto sensu em outros ramos relacionados.

Os participantes relataram que havia certo preconceito por parte da rede pública e privada em contratar um egresso do programa de Enfermagem em Psiquiatria e Saúde Mental, pois tendiam a ser vistos como "enfermeiros sem prática clínica". Este ponto foi apontado na fala do Egresso 3:

Até para trabalhar na área bospitalar é dificil, porque mesmo a gente passando pelo bospital psiquiátrico, a gente não vê as situações clínicas do paciente, sem contar que a gente se distancia das práticas clinicas de Enfermagem durante a residência.

A dificuldade em conseguir oportunidades no campo de trabalho da saúde mental levou alguns dos participantes a procurarem especializar-se em outras áreas. Eles relataram que a busca foi unicamente para aumentar suas chances quanto à empregabilidade.

\footnotetext{
Eu mesmo tô partindo para outra área, para urgência e emergência, por exemplo. E se eu digo que tenbo especialização em Saúde Mental, isso praticamente não serve de nada. Eu tenho que me especializar em outra coisa para trabalhar. (Egresso 2).
}

Um aspecto de destaque que, mesmo diante das dificuldades relatadas, esteve marcado nas falas, foram os sentimentos de satisfação pelo campo da Saúde Mental. Alguns manifestaram 
que tudo o que conquistaram, toda a bagagem profissional e acadêmica deveu-se ao tempo que passaram no programa de residência.

Tudo o que eu tenho hoje, posso dizer, sem sombra de dúvida, que foi graças à residência. No início foi difícil, porque eu não conseguia trabalbo na área, mas eu continuei estudando e hoje eu estou onde estou por conta da residência em Saúde Mental. Toda a bagagem que tive na residência, eu uso na sala de aula. (Egresso 8).

Segundo os relatos, para os que se direcionaram para a docência, foi um diferencial ter passado pelo programa e pela experiência do trabalho nos serviços de Saúde Mental. Tal aspecto foi apontado como relevante para a qualidade do ensino teórico-prático desse docente. É o que aponta o relato do Egresso 4:

\begin{abstract}
Olha, tudo o que eu sei boje e que aplico na sala de aula é graças à residência, viu? A experiência que eu tive na residência, trabalhar os grupos terapêuticos, fazer o PTS [Projeto Terapêutico Singular], discutir os casos, tudo mesmo, eu levo da experiência que eu tive nos serviços, e isso enriquece muito o meu trabalho como professora.
\end{abstract}

Em contrapartida, alguns participantes manifestaram descontentamento com a escolha do programa de Saúde Mental, não pela área em si, mas pelas poucas oportunidades que encontraram para inserir-se no campo de trabalho. Escolher outra área da residência em Enfermagem teria sido a opção mais assertiva, se soubessem da falta de oportunidades antecipadamente.

Para ser bem sincera, boje eu me arrependo. Não pela Saúde Mental, porque é uma paixão minha; é uma área que eu gosto e que eu tenho interesse e que eu trabalbaria pela minha vida todinha. Por mais que traga muitas frustrações [...] eu gosto e me identifico. Agora, assim, com relação ao campo de trabalbo, que já sinalizava para mim no começo, eu não faria. Escolberia outra residência. Mas só pelas possibilidades de trabalbo, não pela Saúde Mental em si. (Egresso 2).

Assim, é evidente a dualidade entre sentir-se satisfeito com as possibilidades de conhecimento que a vivência na residência proporcionou e sentir-se frustrado com a ausência de aproveitamento pelo campo de trabalho de um profissional especializado.

\section{Discussão}

Os resultados deste estudo apontam a existência de dualidades na perspectiva do enfermeiro egresso de um programa de residência em Enfermagem Psiquiátrica e Saúde Mental sobre a formação e o campo de trabalho. A primeira, diz respeito às expectativas geradas antes da entrada no programa versus a realidade do processo de formação vivido. A segunda, refere-se à satisfação profissional gerada com a experiência versus a falta de oportunidades no campo de trabalho após a formação.

Com relação às expectativas geradas no ingresso em um programa de residência, os relatos indicaram que há conflitos expressos entre a realidade esperada e a vivida, uma vez que, ao mesmo tempo em que esses são profissionais formados, aptos a exercerem a profissão, verifica-se o anseio em muitos de serem acompanhados em suas decisões e supervisionados pela presença contínua de um professor. Portanto, a exigência de ações autônomas pelos preceptores pode gerar insegurança e insatisfação.

Por outro lado, foi possível detectar a frequente fragilidade no entendimento dos profissionais dos serviços quanto ao papel dos residentes. Era como se o papel desses fosse apenas o preenchimento de lacunas do pessoal efetivo, o que reforça o discurso de sobrecarga e abandono no aspecto formativo. Ficou evidenciando, assim, o conflito entre o residente "estudante" e o residente "profissional"(9).

Essas questões poderiam ser melhor conduzidas se houvessem pactuações mais efetivas entre os serviços e as instituições de ensino. Esses acordos poderiam promover maior compreensão do impacto de um programa de residência enquanto colaborador na atualização dos profissionais de uma instituição e na formação dos profissionais que estivessem se qualificando no campo da saúde mental.

Em relação ao "choque" que os residentes relataram sentir ao vivenciar os serviços na RAPS, pode haver relação com mudança de concepção de atenção à saúde da pessoa com sofrimento ou transtorno mental no Brasil com base na Reforma Psiquiátrica. Essa mudança altera de forma drástica a forma do fazer em saúde mental, incorporando elementos como humanização, liberdade, autonomia, redução de danos, entre 
outros, para promoção e manutenção do respeito aos direitos humanos e dignidade desse público, que não havia antes ${ }^{(4,10-11)}$.

Sobre a diversidade de cenários para a atuação do residente, é possível utilizar toda a RAPS de um município como cenário de práticas, e não apenas uma instituição. Essa variação enriquece os processos formativos, inclusive para trabalhadores da saúde mental que já estão inseridos na rede $^{(12)}$. Este aspecto pode estar vinculado, entre outros fatores, à não interiorização de seu papel na equipe multiprofissional no âmbito da saúde mental no processo da Reforma Psiquiátrica, potencializado por uma formação lacunar. Até porque, diante de todo o arcabouço da reforma sanitária, muitos docentes, no ensino de saúde mental, ainda têm dificuldades de abandonar certas práticas (medicalizantes e excludentes) de cuidado das pessoas em sofrimento psíquico e incorporar a importância da atenção primária a este nicho ${ }^{(12-13)}$.

Quanto à insuficiência de atividades interdisciplinares no ambiente hospitalar, relatada pelos participantes, aponta que a falta de comunicação e de entendimento quanto à necessidade do trabalho em equipe provoca ações individualizadas e desarticuladas, evidenciando que as ações podem não estar comprometidas com as necessidades dos pacientes, mas, sim, com as necessidades institucionais ${ }^{(14)}$.

$\mathrm{Na}$ formação dos residentes, o conceito de interdisciplinaridade deve ser valorizado e explorado, para que eles possam compreender os diferentes modelos de prática na saúde mental, tanto no campo político como no assistencial, em que pese as transformações históricas ocorridas desde a Reforma Psiquiátrica e o surgimento de novos locais de tratamento ${ }^{(14)}$.

Outro aspecto trazido pelos participantes do estudo foi a frustração por não conseguirem postos de trabalho vinculados à RAPS em Alagoas. Isso pode estar relacionado com o fato de a RAPS em Alagoas ter tido uma diminuição considerável no seu crescimento na última década, com pouco investimento na ampliação dos serviços existentes e instituição de novos serviços. Desse modo, há poucos postos a serem ofertados para novos profissionais.
Em discordância quanto a esse aspecto, pesquisa desenvolvida em Minas Gerais aponta que grande parte dos profissionais que concluem o programa em estudo, na residência multiprofissional em saúde mental, segue trabalhando na RAPS $^{(12)}$. De todo modo, é preciso considerar que, na residência multiprofissional, existem outras categorias profissionais, o que não ocorria do programa alvo deste estudo, que é específico para enfermeiros. Este aspecto pode influenciar na absorção desses egressos pelo campo de saúde local.

Ainda assim, é válido ponderar até que ponto os gestores em saúde alagoanos de fato compreendem o papel do enfermeiro especialista em saúde mental para a qualificação do cuidado nessa área. Se isso ocorresse, os egressos dessa formação seriam absorvidos pelo campo de trabalho e não precisariam migrar para outras áreas de atuação.

Os participantes relataram ainda terem percebido a dificuldade de alguns enfermeiros em saber o seu devido papel no âmbito da saúde mental. Essa percepção corrobora resultados de estudos que identificaram, em pesquisas envolvendo enfermeiros atuantes em CAPS e Unidades Básicas de Saúde, o despreparo para a assistência em Saúde Mental e as dificuldades em identificar/delimitar o trabalho do enfermeiro em Saúde Mental ${ }^{(15-16)}$.

Muitas vezes, nota-se que a falta de experiência e a ausência de formação específica para a atuação em serviços complexos, como os de saúde mental, podem criar um distanciamento entre os seus trabalhadores e os pressupostos básicos da atenção psicossocial. Este é um processo que objetiva a (re)introdução do indivíduo nas atividades familiares e sociais, oportunizando a educação e o trabalho com valor por meio de um planejamento. Estes são alicerces necessários nos serviços de atenção à saúde mental, sob a égide da Reforma Psiquiátrica. Se considerar-se ainda a não inclusão de um ambiente formativo nesses serviços, esse distanciamento pode aumentar significativamente ${ }^{(17)}$.

No entanto, um estudo conclui que, quanto mais consciente for o profissional sobre sua condição pessoal e seu papel de trabalhador 
inserido num contexto social, de cidadão num sistema político, mais apto estará para eleger instrumentos de trabalho que resgatem mais pessoas com transtornos mentais, para que possam ser incluídas na mesma condição de sujeito-cidadão $^{(18)}$.

Já no que diz respeito à atuação dos participantes em ambientes comunitários e vinculados à gestão local, a riqueza de aprendizado nesses momentos é apontada em estudo, ao identificar que o residente, com base na análise de problemas, discute e avalia com a equipe daquele local suas ações e a dos demais atores da RAPS. Essa forma de atuação favorece a construção coletiva de projetos de intervenção e possibilita sentir-se gratificado ${ }^{(12)}$.

Outro ponto de convergência na fala dos participantes refere-se à busca do conhecimento, de forma autônoma, com base nas vivências significativas proporcionadas pelo cenário de prática. Esta perspectiva aproxima-se do postulado freiriano, no qual a educação, enquanto prática libertadora no contexto de ensino democrático, deve ser problematizadora e fundamentada na relação dialógica entre educador e educando e no referencial ético-político da Educação Permanente, na qual o sujeito é ator reflexivo e construtor do seu próprio conhecimento ${ }^{(3)}$.

A existência de sobrecarga de trabalho vinculada ao curso da residência foi apontada pelos participantes. Este aspecto corrobora o estudo realizado com residentes multiprofissionais, no qual é apontado que a maioria dos pesquisados apresentou sintomas de estresse em nível considerado não saudável. O predomínio de sintomas psicológicos, tais como cansaço excessivo, vontade de fugir de tudo, angústia/ansiedade diária e dúvida quanto a si próprio, pode sinalizar sofrimento psíquico e problemas na saúde $^{(19)}$. Os autores ainda apontam que um dos fatores que causava insatisfação era a dificuldade de reconhecimento por parte da equipe acerca do trabalho que os residentes desempenhavam, o que colaborava para o sofrimento mental desses $^{(19)}$. Esta afirmação corrobora os achados desta pesquisa, considerando que os participantes relataram não se sentirem contemplados no trabalho vivenciado no ambiente hospitalar, o que pode estar influenciando no desgaste mental mencionado.

Deve-se considerar que questões de gênero e socioeconômicas dos trabalhadores em enfermagem influenciam negativamente em sua participação nas lutas políticas por conquistas trabalhistas. Tendo em vista que nove dos dez participantes desta pesquisa eram do gênero feminino, a despolitização, acomodação e apatia social como consequências de um somatório de características desfavoráveis a respeito da mulher promovem o afastamento da enfermagem dos movimentos de luta e reivindicações, favorecendo a intensificação da precarização laboral ${ }^{(20)}$.

Os participantes comentaram de forma bem expressiva a falta de postos de trabalho no âmbito da saúde mental em Alagoas, fato que os levou a migrar para outros ramos de atuação, como a docência. Entretanto, estudo comprova, mediante levantamento do perfil do trabalho em Enfermagem no Brasil, que o baixo crescimento na empregabilidade entre os enfermeiros faz parte de algo premeditado, no qual é adotada a política de manter percentuais baixos de enfermeiros na composição das equipes de Enfermagem, desconsiderando que este fato gera sobrecarga de trabalho ${ }^{(21)}$.

Muitos participantes desta pesquisa evidenciaram a atividade de docência como opção para a não empregabilidade nas instituições da RAPS. Entende-se que todo professor de enfermagem necessariamente é enfermeiro, mas nem todo enfermeiro detém conhecimentos e habilidades para atuar como professor, uma vez que os conhecimentos mobilizados para o ensino diferem estruturalmente das atividades apenas de assistência ${ }^{(22)}$. Neste sentido, não há uma polarização entre o saber e o saber-fazer por parte dos participantes, ao afirmarem estar satisfeitos com a atuação como professores, uma vez que se sentiam preparados por suas vivências anteriores, que favoreceram a vinculação entre teoria e prática de forma assertiva.

Embora os participantes manifestassem contentamento em compartilhar seus conhecimentos com a esfera acadêmica, é preciso atentar para o 
fato de que o professor-enfermeiro está atrelado à cultura da performatividade. Esta ocorre quando um profissional trabalha para ter um alto desempenho e resultados maiores do que os esperados pelo mercado de trabalho. Então, essa cultura tem servido para avaliar o seu trabalho pelo alcance de metas quantitativas impostas pelo modelo gerencialista. Tal modelo tem se consolidado no Estado neoliberal brasileiro, determinando as regras para o funcionamento das instituições de ensino superior. No caso dos professores-enfermeiros, têm sido impulsionados a adotar a perspectiva gerencialista como diretriz no ensino ${ }^{(22)}$.

Sobre a falta de formação dos preceptores, estudo já havia alertado que esse despreparo para lidar com demandas gerais dos programas dificulta a realização das práticas em saúde e gera angústia nos residentes ${ }^{(19)}$. A literatura aponta que o enfermeiro que atua no ramo da saúde mental nem sempre recebeu formação pautada nos moldes da Reforma Psiquiátrica em sua graduação. Esse processo de mudança curricular expressa uma disputa em relação à manutenção de uma formação focalizada no modelo político-ideológico ou dirigida para a emancipação e, portanto, apoiada em um modelo crítico e transformador ${ }^{(23)}$.

Neste sentido, há a necessidade latente de repensar o currículo dos cursos de Enfermagem. É preciso que esse tema não ocorra transversalmente, mas, sim, esteja sustentado em disciplinas teórico-práticas, com cargas horárias que possibilitem o desenvolvimento de habilidades, conhecimentos e atitudes necessárias para que os egressos possam atuar de forma resolutiva nos diferentes pontos de cuidado, em especial na RAPS ${ }^{(24)}$.

Em relação à organização dos momentos teóricos, apontada como um dos pontos frágeis do processo de formação, considera-se que esses aspectos devem estar definidos no Projeto Pedagógico do Curso (PPC) dos cursos. Assim, o PPC precisa deixar claro de que forma e em que momento deverá ser realizado, além de constar o papel dos residentes, do preceptor, os desfechos de aprendizagem e demais aspectos relacionados à formação.
Estudo $^{(25)}$ traz que a residência em área profissional da saúde tem se concretizado por meio do exercício profissional supervisionado, realizado nos serviços de saúde que, teoricamente, são favoráveis à aprendizagem do residente. Ainda que esforços estejam sendo intensificados para aproximar a perspectiva pedagógica da linha do cuidado, os residentes têm se deparado com barreiras e limites relacionados à construção de um currículo que acompanha o modelo fragmentado de educação e de relacionamentos com os profissionais atuantes no campo de prática, entre outros.

Os participantes citaram o não acolhimento satisfatório por parte de alguns atores presentes no campo de prática. Este achado corrobora o resultado de estudo ${ }^{(25)}$, no qual é apontado que o não acolhimento da equipe, juntamente com a coordenação, preceptores e tutores do Programa, foi referido como fator dificultador para a aquisição de competências e habilidades. Equipes e atores do programa que tenham perfil para o processo educativo baseado na pedagogia crítica problematizadora, com metodologias ativas e libertadoras, foram alternativas apontadas pelos egressos para o melhor aproveitamento do residente durante a sua formação

Sobre o não reconhecimento do papel do residente no campo de prática, estudo aponta que os Programas de Residência, pelas definições do Ministério da Educação, devem estar vinculados às Universidades ou a outras instâncias formativas. No entanto, devem trazer também um alerta para que o processo formativo esteja atento à não (re)produção de mão de obra para o trabalho dos serviços/instâncias, quando residentes são chamados para tapar buraco ou para cumprir atribuições que, muitas vezes, não são inerentes a seu papel ${ }^{(26)}$.

Em busca da superação da dificuldade mencionada pelos participantes da pesquisa em relação a não serem absorvidos pelo campo de trabalho específico da saúde mental, devem haver estudos das necessidades locorregionais, a fim de embasar a abertura de novas vagas nos programas de residência e, assim, colaborar para o aproveitamento da força de trabalho especializada nos serviços relacionados à RAPS ${ }^{(26)}$. 
Entende-se que a Residência, como formação profissional, é importante. Contudo, outros autores $^{(25)}$ sugerem melhorias que precisam ser implementadas para o seu desenvolvimento, como o aprimoramento das relações interpessoais, das condições de trabalho e ampliação do desenvolvimento das competências para administração e gerenciamento.

Este estudo teve como limitações ser a retratação de um programa específico de um único estado brasileiro e apenas para uma categoria profissional, podendo existir características distintas nos demais. Além disso, também foi limitante a insuficiência de produções sobre as residências em saúde mental específicas para enfermeiros, pois grande parte dos estudos estavam voltados para as residências multiprofissionais.

\section{Considerações Finais}

Com base nos resultados e para responder ao objetivo, este estudo permitiu constatar-se a dualidade entre sentir-se satisfeito com as possibilidades de conhecimento que a vivência na residência proporcionou e sentir-se frustrado com a ausência de aproveitamento de um profissional especializado e apto a contribuir para a qualificação do serviço no mercado de trabalho.

Dentre os pontos positivos da residência em saúde mental, os enfermeiros comentaram sobre a quebra de paradigma em relação à assistência à pessoa com transtorno mental em Alagoas e a ampliação de consciência em relação ao seu fazer no campo da saúde mental. Dentre os pontos negativos em relação às atribuições dos residentes, foi criticada a perspectiva centrada no conhecimento técnico, com poucos momentos de problematização de questões profissionais durante o curso, além do aspecto técnico e da falta de postos de trabalho que absorvam esse profissional.

Considera-se essencial o aprofundamento, em novos estudos, que desvelem as relações entre a atuação do enfermeiro no campo da saúde mental, bem como os impactos da atuação desses profissionais para o fortalecimento da RAPS brasileira, e a continuidade do processo de transformação do cuidado orientado pela Reforma Psiquiátrica.

Esta pesquisa contribuiu ainda para o conhecimento sobre as residências específicas para enfermeiros na área da saúde mental, possibilitando a análise e a avaliação do referido programa, na perspectiva da organização e da estrutura, dos processos formativos no ensino teórico e dos serviços nos quais os residentes realizam as atividades e o trabalho. Tornou possível, também, visualizar e compreender as expectativas dos residentes referentes ao campo de atuação e ao mercado de trabalho para enfermeiros que escolhem a área da saúde mental.

\section{Colaborações:}

1 - concepção, projeto, análise e interpretação dos dados: John Victor dos Santos Silva, Thyara Maia Brandão e Amanda Cavalcante de Macêdo;

2 - redação do artigo e revisão crítica relevante do conteúdo intelectual: John Victor dos Santos Silva, Thyara Maia Brandão, Amanda Cavalcante de Macêdo, Keila Cristina Pereira do Nascimento Oliveira, Mara Cristina Ribeiro e Ronildo Alves dos Santos;

3 - aprovação final da versão a ser publicada: John Victor dos Santos Silva, Thyara Maya Brandão, Amanda Cavalcante de Macêdo, Keila Cristina Pereira do Nascimento Oliveira, Mara Cristina Ribeiro e Ronildo Alves dos Santos.

\section{Referências}

1. Amarante $P$, Nunes MO. Psychiatric reform in the SUS and the struggle for a society without asylums. Ciênc saúde coletiva. 2018;23(6):2067-74. DOI: 10.1590/1413-81232018236.07082018

2. Silva JVS, Bandão TM. Contribuições de uma residência em psiquiatria e saúde mental na formação dos enfermeiros egressos. Enferm Foco. 2019;10(6):57-62. DOI: 10.21675/2357-707X.2019. v10.n6.2334

3. Rodrigues JM, Menezes TMO, Rosa DOS, Freitas AVS, Prado ML. Political and pedagogical projects of nursing residency to the elderly from Paulo Freire's perspective. 
Rev Bras Enferm. 2019;72(Suppl2):36-42. DOI: $10.1590 / 0034-7167-2017-0683$

4. Wetzel C, Kohlrausch ER, Pavani FM, Batistella FS, Pinho LB. Analysis of interprofessional in-service education in a Psychosocial Care Center. Interface (Botucatu). 2018;22(Suppl2):1729-38. DOI: $10.1590 / 1807-57622017.0664$

5. Fernandes JD, Sadigursky D, Silva RMO, Amorim AB, Teixeira GAS, Araújo MCF. Teaching psychiatric nursing/mental health: its interface with the Brazilian Psychiatric Reform and national curriculum guidelines. Rev esc enferm USP. 2009;43(4):962-8. DOI: 10.1590/ S0080-62342009000400031

6. Minayo MCS. O desafio do conhecimento: pesquisa qualitativa em saúde. 13a ed. São Paulo: Hucitec; 2013.

7. Tong A, Sainsbury P, Craig J. Consolidated criteria for reporting qualitative research (COREQ): a 32-item checklist for interviews and focus groups. Int J Qual Health Care. 2007;19(6):349-57. DOI: $10.1093 /$ intqhe/mzm042

8. Fontanella BJB, Ricas J, Turato ER. Amostragem por saturação em pesquisas qualitativas em saúde: contribuições teóricas. Cad Saúde Pública. 2008;24(1):17-27. DOI: 10.1590/S0102311X2008000100003

9. Araújo TAM, Vasconcelos ACCP, Pessoa TRRF, Forte FDS. Multiprofissionalidade e interprofissionalidade em uma residência hospitalar: o olhar de residentes e preceptores. Interface (Botucatu). 2017;21(62):601-13. DOI: 10. 1590/1807-57622016.0295

10. Nunes MO, Lima Júnior JM, Portugal CM, Torrenté M. Psychiatric reform and counter-reform: an analysis of a socio-political and sanitary crisis at national and regional level. Ciênc saúde coletiva. 2019;24(12):4489-98. DOI: $10.1590 / 1413-812320182412.25252019$

11. Ramos DKR, Paiva IKS, Guimarães J. Pesquisa qualitativa no contexto da Reforma Psiquiátrica brasileira: vozes, lugares, saberes/fazeres. Ciênc saúde coletiva. 2019;24(3):839-52. DOI: 10.1590/1413-81232018243.00512017

12. Lima ICBF, Passos ICF. Residências integradas em saúde mental: para além do tecnicismo. Trab educ saúde. 2019;17(2):e0020940. DOI: 10.1590/1981-7746-sol00209

13. Martins GCS, Peres MAA, Santos TCF, Queirós PJP, Paiva CF, Almeida Filho AJ. Teaching undergraduate nursing in mental health as allied to the consolidation of the Psychiatric Reform movement. Esc Anna Nery. 2018;22(4):e20180164. DOI: $10.1590 / 2177-9465-$ ean-2018-0164

14. Souza ACS, Ribeiro MC. A interdisciplinaridade em um CAPS: a visão dos trabalhadores. Cad Ter Ocup. 2013;21(1):91-8. DOI: 10.4322/cto.2013.013

15. Almeida PA, Mazzaia MC. Nursing Appointment in Mental Health: experience of nurses of the network. Rev Bras Enferm. 2018;71(Suppl 5):2154-60. DOI: 10.1590/0034-7167-2017-0678

16. Nicacio TR, Toledo VP, Garcia APRF. From alienation to the nursing clinic: care of patients with psychiatric comorbidity. Rev Bras Enferm. 2018;71(Suppl5):2229-36. DOI: 10.1590/0034-7167-2017-0930

17. Ribeiro MC. Psychosocial care center workers in Alagoas, Brazil: interstices of new practices. Interface (Botucatu). 2015;19(52):95-108. DOI: $10.1590 / 1807-57622014.0151$

18. Elias ADS, Tavares CMM, Muniz MP. The intersection between being a nurse and being a therapist in Mental Health. Rev Bras Enferm. 2020;73(1):e20180134. DOI: 10.1590/0034-7167-2018-0134

19. Silva RMB, Moreira SNT. Estresse e Residência Multiprofissional em Saúde: Compreendendo Significados no Processo de Formação. Rev bras educ med. 2019;43(4):157-66. DOI: 10.1590/1981-52712015v43n4rb20190031

20. Macedo RM. Resistência e resignação: narrativas de gênero na escolha por enfermagem e pedagogia. Cad Pesqui. 2019;49(172):54-76. DOI: 10.1590/198053145992

21. Silva MCN, Machado MH. Health and Work System: challenges for the Nursing in Brazil. Ciênc saúde coletiva. 2020;25(1):7-13. DOI: https://doi. org/10.1590/1413-81232020251.27572019

22. Gatto Jr JR, Fortuna CM, Sousa LA, Santana FR. Nursing professor in higher education: time, money and resistance in the management vision. Texto contexto - enferm. 2020;29:e20180407. DOI: 10.1590/1980-265x-tce-2018-0407

23. Olmos CEF, Rodrigues J, Lino MM, Lino MM, Fernandes JD, Lazzari DD. Psychiatric nursing and mental health teaching in relation to Brazilian curriculum. Rev Bras Enferm. 2020;73(2):e20180200. DOI: $10.1590 / 0034-7167-2018-0200$

24. Pereira MO, Reinaldo AMS, Villa EA, Gonçalves AM. Overcoming the challenges 
to offer quality training in psychiatric nursing. Rev Bras Enferm. 2020;73(1):e20180208. DOI: 10.1590/0034-7167-2018-0208

25. Ramos TM, Rennó HMS. Training in the nursing residency in Primary Care/Family Health from the perspective of the graduates. Rev Gaúcha Enferm. 2018;39:e2018-0017. DOI: https://doi. org/10.1590/1983-1447.2018.2018-0017
26. Onocko-Campos R, Emerich BF, Ricci EC. Residência Multiprofissional em Saúde Mental: suporte teórico para o percurso formativo. Interface (Botucatu). 2019;23:e170813. DOI: 10.1590/interface. 170813

Recebido: 5 de outubro de 2020 Aprovado: 12 de janeiro de 2021

Publicado: 5 de fevereiro de 2021

A Revista Baiana de Enfermagem utiliza a Licença Creative Commons - Atribuição-NãoComercial 4.0 Internacional. https://creativecommons.org/licenses/by-nc/4.0/ Este artigo é de acesso aberto distribuído sob os termos da Licença Creative Commons (CC BY-NC). Esta licença permite que outros remixem, adaptem e criem a partir do seu trabalho para fins não comerciais. Embora os novos trabalhos tenham de lhe atribuir o devido crédito e não possam ser usados para fins comerciais, os usuários não têm de licenciar esses trabalhos derivados sob os mesmos termos. 